\title{
The effect of the first vaginal birth on pelvic floor anatomy and dysfunction
}

\author{
Iva Urbankova ${ }^{1,2} \cdot$ Klara Grohregin $^{1} \cdot$ Jiri Hanacek ${ }^{1} \cdot$ Michal Krcmar $^{1} \cdot$ Jaroslav Feyereisl $^{1} \cdot$ Jan Deprest $^{2}$. \\ Ladislav Krofta ${ }^{1}$ (B)
}

Received: 2 October 2018 / Accepted: 27 June 2019 / Published online: 20 July 2019

(C) The Author(s) 2019

\begin{abstract}
Introduction and hypothesis First vaginal delivery severely interferes with pelvic floor anatomy and function. This study determines maternal and pregnancy-related risk factors for pelvic floor dysfunction (PFD), including urinary incontinence (UI), urgency, anal incontinence (AI), pelvic organ prolapse (POP) and levator ani muscle (LAM) avulsion.

Methods This is a single-centre prospective observational cohort study on healthy women in their first singleton pregnancy. All underwent clinical and 3D transperineal ultrasound examination at 6 weeks and 12 months postpartum. Objective outcomes were POP-Q and presence or absence of LAM trauma. Functional outcomes were measured by the ICIQ-SF and PISQ 12. Multivariate regression was performed to determine birth and maternal habitus-related risk factors for UI, urgency, AI, dyspareunia, LAM avulsion and ballooning.

Results Nine hundred eighty-seven women were included. Risk factors for UI were maternal age per year of age (OR: 1.09; $95 \%$ CI: $1.04-1.13 ; p=0.0001$ ) and BMI before pregnancy (OR: 1.08; 95\% CI: 1.04-1.13; $p=0.001$ ); for POP stage II+ maternal age (OR: $1.08 ; 95 \%$ CI: $1.08-1.14 ; p=0.005$ ). Avulsion was more likely after forceps (OR: 3.22; 95\% CI:1.54-8.22; $p=0.015$ ) but less likely after epidural analgesia (OR: $0.58 ; 95 \% \mathrm{CI}: 0.37-0.90 ; p=0.015)$ and grade I perineal rupture (OR: $0.50 ; 95 \% \mathrm{CI}$ : $0.29-0.85 ; p=0.012$ ). Ballooning was more likely at increased maternal age (OR: $1.08 ; 95 \%$ CI: $1.02-1.13 ; p=0.005$ ), epidural (OR: $1.64 ; 95 \%$ CI: $1.06-2.55 ; p=0.027)$ and grade I perineal rupture (OR: $1.79 ; 95 \%$ CI: $1.10-2.90 ; p=0.018)$.

Conclusion Though maternal characteristics at birth such as age or BMI increase the risk of PFD, labour and birth factors play a similarly important role. The most critical risk factor for MLA avulsion was forceps delivery, while an epidural had a protective effect.
\end{abstract}

Keywords BMI $\cdot$ Forceps $\cdot$ Incontinence $\cdot$ Maternal age $\cdot$ Pelvic organ prolapse

\section{Introduction}

Pelvic floor dysfunction (PFD), such as pelvic organ prolapse (POP), urinary (UI) and anal incontinence (AI), affects many

Electronic supplementary material The online version of this article (https://doi.org/10.1007/s00192-019-04044-2) contains supplementary material, which is available to authorized users.

Ladislav Krofta

ladislav.krofta@upmd.eu

1 Institute for the Care of Mother and Child and Third Faculty of Medicine, Charles University, Podolske nabrezi 157, 14700 Prague, Czech Republic

2 Department of Development and Regeneration, Organ systems cluster, Group Biomedical Sciences, and Pelvic Floor Unit, University Hospitals KU Leuven, Leuven, Belgium women worldwide with millions of them undergoing corrective surgery at significant expense and personal suffering [1]. Many risk factors for development and symptom progression were identified, and many of them are shared by different PFDs [2]. According to DeLancey's lifespan model, PFD becomes symptomatic when the pelvic floor function drops under a certain threshold level [3]. Following an initial drop caused by pregnancy and birth, other risk factors such as lifestyle, smoking, being overweight and chronically increased intra-abdominal pressure negatively affect its function. In most women, PFD becomes symptomatic after several decades, but women with severe pelvic floor trauma may become symptomatic shortly after their first birth.

The most frequently shared risk factor for all PFDs is vaginal birth. Apart from the effects of pregnancy, vaginal birth additionally interferes directly with all structures and tissues of the pelvic floor [4]. The detrimental nature of the impact of 
vaginal delivery is even more pronounced in the case of forceps extraction to complete the second stage of labour [5]. Other obstetric risk factors include high foetal birth weight, a prolonged second stage of labour and high BMI [6]. Some studies had also described high maternal age at the time of first birth, but that is controversial $[7,8]$.

To contribute to the study of the effects of vaginal birth, we set up a large prospective cohort study of unselected nulliparous women, which we followed from birth to 1 year postpartum. Herein we correlate the demographic and obstetric risk factors for the presence of PFD 1 year after the birth. An additional goal was to identify the risk factors for levator ani muscle trauma, as diagnosed by ultrasound, and, if applicable, its contribution to the presence of PFD.

\section{Materials and methods}

This single-centre longitudinal study was designed to recruit a large prospective cohort of healthy women in their first pregnancy, including singleton ones only, and who delivered vaginally at or beyond 37 weeks. All women admitted to the labour suite between May 2011 and July 2013 were invited to participate. Exclusion criteria for entry were being minors, not speaking fluent Czech, being non-Caucasian and post-hoc women who became pregnant during follow-up. Women who delivered with unscheduled caesarean section will be reported separately. The institutional ethics committee approved this study, and all women gave written informed consent.

\section{Follow-up and outcome measures}

Before discharge from the birth unit, we asked consenting women about the presence of involuntary leakage of urine or stools before and during pregnancy. Study visits were arranged 6 weeks and 1 year after birth. At these, they were asked about PFD, and they were assessed by one of four experienced nurses from the urogynaecological clinic. Women filled out two validated questionnaires, i.e., the short form of the International Consultation on Incontinence Questionnaire (ICIQ-SF) and Pelvic Organ Prolapse/Urinary Incontinence Sexual Questionnaire (PISQ12) (Czech version) $[9,10]$. Women were also explicitly asked if they had any anal and urinary incontinence and dyspareunia. The anatomical assessment was by the pelvic organ prolapse score (POP-Q) [11] and stage and pelvic floor muscle strength assessment by the Oxford scale [12]. Herein clinically significant POP will be defined as the occurrence of stage II+ prolapse (leading point of the prolapse at least at POP-Q point 0 or further) [13]. Transperineal pelvic floor ultrasound (TPUS) was performed as described by Dietz et al. [14] (4.0-9.0-MHz probe, Voluson Expert E8, General Electric, Zipf, Austria). Briefly, the probe was placed vertically over the perineum. A two 4D loop including "squeeze-relaxation-Valsalva manoeuvre-relaxation" was recorded and stored for offline assessment. The nurses had $\geq 3$ years of experience with TPUS and clinical evaluation of PFD. Three other similarly qualified observers not involved in the earlier clinical or ultrasound assessment read the TPUS volumes offline (4DView, GE). All observers evaluated the first 55 cases, and their intraclass correlation and kappa coefficient were calculated to confirm their agreement (supplementary Table 1). Later, each case was evaluated by one observer.

The better loop was used for the evaluation and measurement of the genital hiatus at minimum hiatal diameter during contraction and Valsalva and at rest. The levator ani avulsion was identified in tomographical sections centred around the level of minimal hiatal dimension. A set of eight slices was obtained in the axial plane at $2.5-\mathrm{mm}$ intervals from $5 \mathrm{~mm}$ below to $12.5 \mathrm{~mm}$ above the plane of minimal hiatal dimension. The LAM avulsion was present if there was a discontinuity of the LAM on the three central slices at the muscle contraction [14]. Ballooning was defined as a genital hiatus area at Valsalva $>25 \mathrm{~cm}^{2}$ [14]. In case of poor image quality, the US was reviewed and evaluated in cooperation with the supervisor (LK).

During postnatal consultations, we recommended all women undergo pelvic floor training (PFT), which is covered by the national health insurance.

Additional demographic, biometric and obstetric data were obtained from the medical records, including onset of labour, use of oxytocin during labour, epidural or other analgesics, length of the first and second stage, spontaneous or instrumental vaginal birth, or, if appropriate, the use of caesarean section, cervical dilation at that moment and the leading indication, and, if applicable, any trauma to the vagina, vulva or anal sphincter. Perineal trauma was categorized as grade I (perineal skin/vaginal mucosa), grade II (fascia, muscles, perineal body) or grade III (grade II + anal sphincter; irrespective of episiotomy) [15].

\section{Birth management}

At our institution, midwives primarily manage most of the first and second stage, but under the supervision of a gynaecologist. We adhere to the principles of "active management of labour" [16]. For pain relief in the first labour stage, either nalbuphine (10 mg/3 h, i.v.) or "delayed walking" epidural analgesia (EDA) consisting of bupivacaine $0.5 \%$ and sufentanil (i.e., cervical dilatation $\geq 4 \mathrm{~cm}$ ) was offered [17]. Following $30 \mathrm{~min}$ in a supine position, the parturient was advised to move and walk actively. If needed, EDA was reloaded every $2 \mathrm{~h}$. Following an uncomplicated first stage, active management of the second stage included encouraging pushing the head down once at stage +3 . Midwives recognized the second stage during a vaginal examination and 
recorded its length. During crowning, perineal protection included manual support and controlled foetal head passage [18]. Left mediolateral episiotomy was performed when it was clinically indicated (i.e., foetal distress, rigid perineum during crowning), but there was no formal policy.

\section{Statistical evaluation}

Data were stored in a purpose-designed database (Office Excel 2007, Microsoft Corp., Redmond, WA, USA) and analysed with SPSS 19.0 (SPSS Inc., Chicago, IL). Only data from women who delivered vaginally were used to determine maternal and obstetrical risk factors for LAM avulsion and PFD 12 months postpartum. Univariate analysis was performed on maternal (age, BMI before pregnancy and at delivery from which the BMI change was calculated) and obstetrical (foetal weight, length of 1st and 2nd stage, type of analgesia, perineal injury, forceps birth, breastfeeding) characteristics. Variables with $p<0.250$ were taken into account for multivariate regression analysis, using a forward elimination of covariates according to the lack of significance. The risk for symptomatic stress UI and POP in women with LAM avulsion was tested using a chi-square test.

\section{Results}

The study included 3648 women, of whom 1359 completed all study visits (drop-out rate: $62.8 \%$ ). Of these, we excluded 24 who became pregnant again within 1 year. Three hundred forty-eight (18.6\%) women who had a caesarean section were not included in this analysis. Finally, we evaluated $987 / 3648$ $(27.0 \%)$ women who delivered vaginally. Tables 1 and 2 display comparison of the demographic and obstetric characteristics of included and excluded women. Included women were older $(+0.8$ year) and were more likely to have had labour induced $(+6 \%)$.

\section{Levator muscles and degree of prolapse}

In most women, the LAM evaluation was possible; in 13 cases, the LAM avulsion was evaluated together with the supervisor. Unilateral LAM avulsion was diagnosed 1 year after delivery in $173(18.1 \%)$. In 89 (9.0\%), this was bilateral. LAM avulsion was predominantly left $(n=109 ; 63 \%)$. Ballooning was present in $309(31.3 \%)$ women, of which 165 (53.3\%) were without LAM avulsion. The POP-Q, average Oxford score and subjective outcome are displayed in Supplementary Table 1. Stage II prolapse in at least one compartment was present in 562 (56.9\%) of which stage II+ was present in $130(23.1 \%)$.

\section{Urinary incontinence and urgency}

Fifty-three (5.4\%) women reported UI before pregnancy. That number increased six-fold during pregnancy to $29.7 \%$ of study participants (Fig. 1). Of those, in one-third (23.4\%) this resolved within 6 weeks after birth, without reappearance within a year. However, after birth an additional 203 women who were previously not incontinent reported UI: this is nearly as many women as developed UI in pregnancy. As a result, 6 weeks postpartum, $40.6 \%(n=401)$ were not dry. Later during that first year, UI resolved in $163(-40.6 \%)$, but 76 $(+19.0 \%)$ women developed de novo incontinence. As a result, in our cohort, $31.8 \%$ of women still reported urinary incontinence after their first vaginal delivery. This population includes $66.0 \%(n=35)$ of the women who reported UI before pregnancy, $41.7 \%(n=100)$ of the women who developed UI during pregnancy, and 50\% $(n=103)$ of the women who developed UI only during the postpartum period. The type of incontinence as picked up by the ICIQ SF (Domain 6) in these 314 women was during coughing and physical exercises in $61 \%$ before getting to the toilet in $20 \%$ and on mixed occasions in $19 \%$.

Twenty-four $(2.4 \%)$ women reported urgency before pregnancy. Their problem persisted in pregnancy, and their number increased four-fold ( $n=96 ; 9.7 \%)$ (Fig. 1). In half of them, the issue resolved in the postpartum period, but 23 women developed de novo urgency after vaginal birth. By 1 year, the problem disappeared in half of the women. By 1 year, $4.8 \%$ of women who delivered vaginally reported urgency, of which half developed this as a new problem.

\section{Anal function}

No women reported AI before or during pregnancy. Other dysfunctions were not quantified. At six weeks after birth, $1.6 \%$ of women reported faecal urgency $(n=2)$, flatus $(n=$ $6)$ or stool $(n=8)$ incontinence. When adding the other forms of anorectal dysfunction, $8.4 \%$ of women reported bother at 6 weeks $(n=83)$. Three-quarters of these dysfunctions resolved by 1 year. AI persisted in only one woman, who sustained perineal rupture grade III. Eight additional women reported first AI between 6 weeks and 1 year after birth (6 urgencies, 2 flatus/stool incontinence). The number of women reporting de novo dyschezia was, however, three times higher $(n=24$; $2.4 \%$ ), which is half as many women reporting urgency incontinence.

\section{Sexual function}

One year postpartum, 961(97.5\%) women were sexually active, of which 169 (17.1\%) reported dyspareunia. Women breastfeeding at 1 year $(421,42.6 \%)$ were more likely (OR: 1.449; 95\%CI: $1.039-2.019, p=0.033$ ) to report dyspareunia. 
Table 1 Demographic and obstetric characteristics of non-responders and responders

\begin{tabular}{|c|c|c|c|c|}
\hline & $\begin{array}{l}\text { Non-responders } \\
n=2313\end{array}$ & $\begin{array}{l}\text { Responders } \\
n=1335\end{array}$ & $p$ & $\begin{array}{l}\text { Study group } \\
n=987\end{array}$ \\
\hline \multicolumn{5}{|l|}{ Demographics } \\
\hline Age (mean $\pm \mathrm{SD}$; years) & $30.0 \pm 4.0$ & $30.8 \pm 3.5$ & 0.0001 & $30.5 \pm 3.4$ \\
\hline Height $($ mean $\pm \mathrm{SD} ; \mathrm{cm})$ & $168.7 \pm 6.2$ & $168.9 \pm 6.3$ & Ns & $169.2 \pm 6.1$ \\
\hline BMI before pregnancy $($ mean \pm SD) & $22.2 \pm 3.4$ & $22.2 \pm 3.3$ & Ns & $21.9 \pm 3.0$ \\
\hline $\mathrm{BMI}$ at the delivery $($ mean $\pm \mathrm{SD})$ & $27.4 \pm 3.9$ & $27.3 \pm 3.7$ & Ns & $27.0 \pm 3.5$ \\
\hline $\mathrm{BMI}$ increase (mean $\pm \mathrm{SD})$ & $5.2 \pm 1.8$ & $5.1 \pm 1.7$ & Ns & $5.1 \pm 1.7$ \\
\hline \multicolumn{5}{|l|}{ Obstetrical characteristics } \\
\hline Foetal weight (mean $\pm \mathrm{SD} ; \mathrm{g})$ & $3357.1 \pm 419.1$ & $3381.6 \pm 420.7$ & Ns & $3362.0 \pm 401.9$ \\
\hline Length of the first stage (mean $\pm \mathrm{SD}$; hh:mm) & $06: 47 \pm 3: 59$ & $06: 53 \pm 04: 06$ & Ns & $6: 52 \pm 04: 07$ \\
\hline Length of the second stage (mean $\pm \mathrm{SD}$; hh:mm) & $00: 44 \pm 00: 34$ & $00: 46 \pm 00: 35$ & Ns & $00: 43 \pm 00: 31$ \\
\hline Elective caesarean section $(n, \%)$ & $77(3.3 \%)$ & $50(3.7 \%)$ & Ns & NA \\
\hline Acute caesarean section $(n, \%)$ & $469(20.3 \%)$ & $297(22.2 \%)$ & Ns & NA \\
\hline Forceps delivery $(n, \%)$ & $37(1.6 \%)$ & $23(1.7 \%)$ & Ns & $23(2.3 \%)$ \\
\hline Vacuum extraction $(n, \%)$ & $4(0.2 \%)$ & $3(0.2 \%)$ & Ns & $3(0.3 \%)$ \\
\hline Labour induction $(n, \%)$ & $454(19.6 \%)$ & $312(23.4 \%)$ & 0.004 & $200(20.3 \%)$ \\
\hline Epidural analgesia $(n, \%)$ & $541(23.4 \%)$ & $304(22.8 \%)$ & Ns & $147(14.9 \%)$ \\
\hline Oxytocin $(n, \%)$ & $1545(66.8 \%)$ & $903(67.6 \%)$ & Ns & $692(70.1 \%)$ \\
\hline Use of analgesics other than epidural $(n, \%)$ & $864(37.4 \%)$ & $525(39.3 \%)$ & Ns & $401(40.6 \%)$ \\
\hline Perineal rupture grade $\mathrm{I}(n, \%)$ & $228(9.9 \%)$ & $110(8.2 \%)$ & Ns & $110(11.1 \%)$ \\
\hline Perineal rupture grade II $(n, \%)$ & $115(5.0 \%)$ & $77(5.8 \%)$ & Ns & $77(7.8 \%)$ \\
\hline Episiotomy $(n, \%)$ & $1219(52.7 \%)$ & $703(52.7 \%)$ & Ns & $703(71.2 \%)$ \\
\hline Perineal rupture grade III $(n, \%)$ & $37(1.6 \%)$ & $30(2.2 \%)$ & Ns & $30(3.0 \%)$ \\
\hline
\end{tabular}

\section{Uni- and multivariate analysis}

We performed five sets of analysis for PFDs and LAM trauma at 12 months, the presence of urinary incontinence, pelvic organ prolapse stage II+, LAM avulsion and LAM ballooning (Tables 3,4). Analysis of anal incontinence was not performed because of its low occurrence.

Urinary incontinence was 1.6 more likely in women with LAM avulsion (95\% CI: 1.175-2.127, $p=0.003$ ). POP stage II+ was more likely in women with LAM avulsion (OR 2.588, 95\% CI: 1.764-3.797, $p=0.0001)$ and with ballooning (OR 2.144, 95\% CI: $1.396-3.293, p=0.0001)$.

\section{Discussion}

\section{Main findings}

One year postpartum the most common PFD was urinary incontinence, reported by every third woman. Risk factors for its development were maternal age, BMI before pregnancy and its increase during pregnancy. The main risk factor for POPII+ was maternal age. LAM injuries were present in $43 \%$ of women. Muscle avulsion was 3.2 more likely in women who had forceps-assisted birth. Surprisingly, there was an opposite effect of EDA and perineal rupture grade I on the LAM avulsion and ballooning.

The study cohort is representative of the population of nulliparous women delivering at the Institute for most parameters. In the study cohort, $70 \%$ of women were administered oxytocin during labour, which is a result of the active labour management, which requires a progression of at least $1 \mathrm{~cm} / \mathrm{h}$ [16]. There were no more details on administration; therefore, we were not able to discriminate between a short and extended application. However, higher maternal age (> 35 years) was shown to increase the likelihood of oxytocin administration two-fold compared with younger women $(<19$ years) [19]. Also strikingly high was the number of episiotomies (71\%), which surpasses the nationally reported rates [20]. We could not identify the possible reasons. There was a relatively low rate of EDA (14\%), forceps/VEX deliveries (2.6\%) and third-degree perineal ruptures (3.0\%), all of which correspond to the long-term institutional and national data [21].

\section{Interpretation}

Pregnancy and not only vaginal birth severely interferes with pelvic floor function. Every fourth woman reported stress UI only due to the pregnancy, which persisted in many of them until 1 year postpartum. After birth, more than one-third of 
Table 2 Objective and subjective outcomes in $n=978$ women in this study. The Oxford score was calculated as the average of right and left muscle strength

\begin{tabular}{lll}
\hline POP Q & Mean & SD; range \\
\hline $\mathrm{Aa}$ & -1.6 & $0.6 ;-3-+1$ \\
$\mathrm{Ba}$ & -1.6 & $0.6 ;-3-+1$ \\
$\mathrm{C}$ & -5.8 & $1.5 ;-7-+1$ \\
$\mathrm{Ap}$ & -1.5 & $0.6 ;-2-+1$ \\
$\mathrm{Bp}$ & -1.5 & $0.7 ;-3-+1$ \\
$\mathrm{~Pb}$ & 3.7 & $0.4 ; 2-7$ \\
$\mathrm{Gh}$ & 3.8 & $0.4 ; 2-5$ \\
$\mathrm{TVL}$ & 8.8 & $0.5 ; 6-10$ \\
Mean Oxford score & 1.4 & $1.1 ; 0-5$
\end{tabular}

\begin{tabular}{lll}
\hline Prolapse stage & $\mathrm{N}$ & $\%$ \\
\hline Anterior stage I & 0 & - \\
Stage II & 349 & $35.5 . \%$ \\
Central stage I & 190 & $19.3 \%$ \\
Stage II & 2 & $0.2 \%$ \\
Posterior stage I & 0 & - \\
Stage II & 423 & $43.0 \%$ \\
& &
\end{tabular}

\begin{tabular}{lll}
\hline Ultrasound findings $\left(\mathrm{cm}^{2}\right)$ & Mean & SD; range \\
\hline Urogenital hiatus on relaxation & 22.8 & $4.2 ; 8.8-37.0$ \\
On valsalva & 28.2 & $6.9 ; 8.22-49.7$ \\
During contraction & 14.5 & $3.6 ; 6.6-30.5$ \\
Urethral gap & 2.4 & $0.4 ; 1.6-4.7$
\end{tabular}

\begin{tabular}{lll}
\hline Questioners & Median/mean & IQR/SD; range \\
\hline ICIQ SF $(n=987)$ & 1.9 & 4 \\
ICIQ SF with UI $(n=314)$ & 5.9 & 4 \\
Amount of urine & 2.0 & 0 \\
UI frequency & 1 & 0 \\
UI visual analogue scale & 2 & 2 \\
PISQ 12 & 38.8 & $4.0 ; 13-47$ \\
\hline
\end{tabular}

asymptomatic women developed UI continuing in two-thirds of them beyond 1 year. Discriminating between the effects of the pregnancy itself and the impact of birth is not possible here.

Further evaluation of women with caesarean section may support the findings of others who have shown an increased risk of UI compared with nulliparas [22]. Similar to other studies, the age at first birth was confirmed to be critical for the development of symptomatic UI [23]. However, its effect attenuates with the actual age and disappears after 50 years of age [24].

Regression of UI during the observational period was probably also affected by promoted physiotherapy, but no more details were collected so we were not able to draw more conclusions. However, recent literature supports PFT as an appropriate treatment for UI even though it may not have a long-lasting effect [25].

For POP evaluation, we chose the more strict criteria because we lacked the subjectively reported outcome $[13,26]$. Chances for POP(II+) increased by $8 \%$ for each additional year of age. Also, women who had LAM avulsion or ballooning were more likely to have POPII+. We did not include this factor in the analysis since it only develops as a result of birth. There is some evidence that mediolateral episiotomy protects against, whereas spontaneous perineal lacerations promote POP development [24]. We did not confirm this observation concerning POP because of either the high episiotomy rate or short observational period.

The underlying conditions for PFD development are direct and indirect injuries to all parts of the pelvic floor. We only investigated LAM. Avulsion was present in almost every third woman and was three-fold more likely in women with forceps delivery, which is similar to the current literature (OR 1.6-4.40) [5]. Unlike others, the unilateral avulsion was predominantly on the left side [27, 28]. Ballooning was often present in women with LAM avulsion, but in the regression, we only include ballooning in those without avulsion. Ballooning is a result of the muscular over-distension, micro-traumatization, pudendal neuropathy and resulting healing [24]. LAM avulsion and ballooning shared three risk factors (EDA, perineal rupture grade I and the second stage) but with opposite effects. The likelihood of LAM avulsion was halved in women who had EDA and who sustained grade I perineal rupture. On the other hand, the muscle is 1.6-fold and 1.8-fold more likely to become overstretched, respectively. The EDA effect could be explained by the resulting muscle relaxation, which becomes less likely to tear but more likely to be overstretched. Our observation could be supported by studies showing a protective effect of EDA on third- and fourthdegree perineal ruptures [29]. EDA also prolonged the second stage of labour and was previously linked with an increased risk of UI [7].

The role of grade I perineal rupture could be explained by compliant tissues allowing sufficient adaptation during crowning. Therefore, LAM avulsion is less likely, whereas overstretching (ballooning) is more likely. Since no prevention of perineal injury has been identified, the explanation could be an individual's physiognomy and intrinsic tissue characteristics such as its composition, compliance and elasticity [30]. These are partially inherited, affected by age, affected by internal diseases, etc. [3]. Indeed, others have also identified age as a risk factor increasing the likelihood of LAM avulsion by $8-10 \%$ for each additional year [8].

\section{Limitations}

The major limitations are the missing questionnaire on POP, missing information on anal incontinence and that they were 
Fig. 1 Development of urinary incontinence (A) and urgency (B)

\section{a Urinary incontinence}
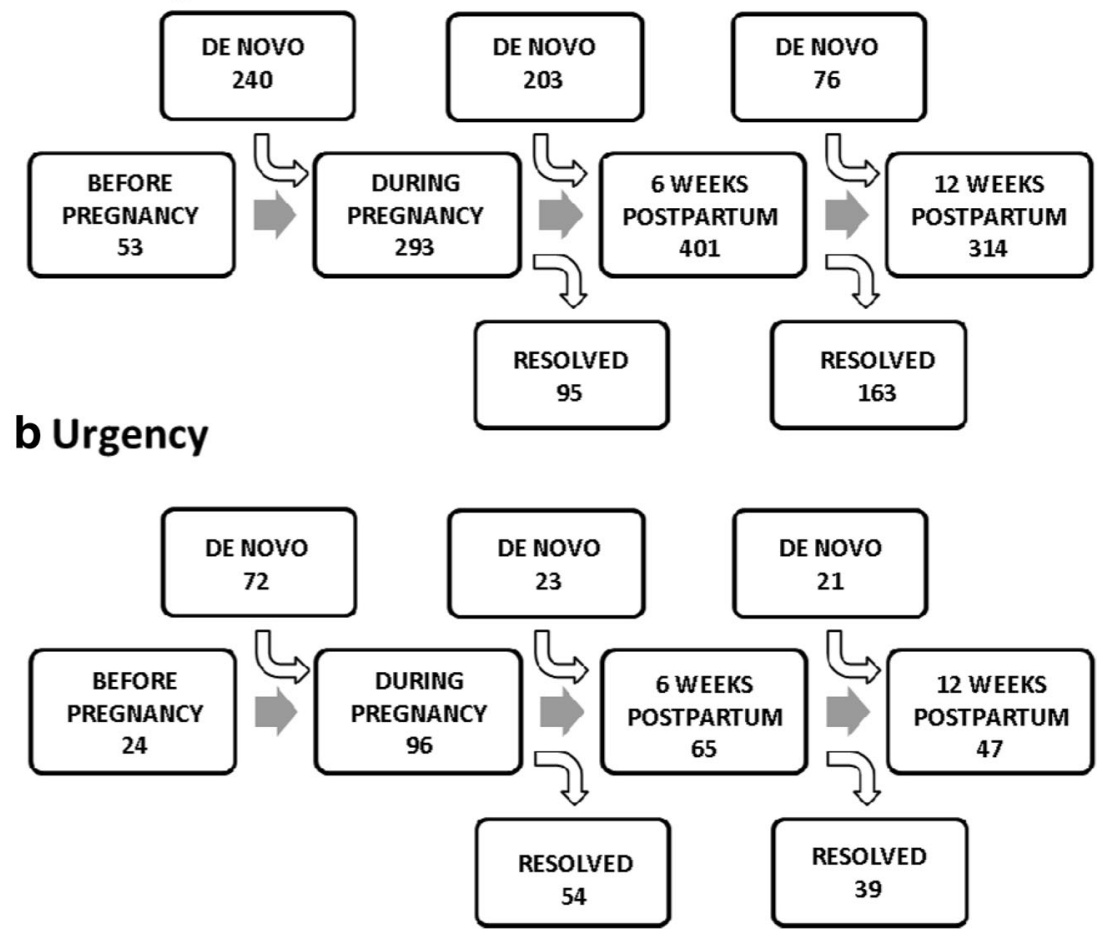

not asked about typical symptoms (vaginal bulge, etc.). To overcome this, in the analysis we only considered POPII+, which includes descent to the level of the hymen or beyond [31]. We also did not prospectively collect subjective complaints on PFD before and during the pregnancy; therefore, these data may be subject to recall bias. We considered the collection of these data at admission inappropriate and not feasible. It would be beneficial also to obtain 3D scans of the anal sphincter to identify occult anal sphincter ruptures. We also did not use any standardized test to categorize the type of UI and relied on subjective reports.
Another limitation is the $63 \%$ drop-out rate, which may have resulted in more women with PFD being included in the study group. During the follow-up, women were contacted and offered another appointment, but many of them did not have time or were not willing to continue the study.

\section{Strengths}

The strengths comprised a large unselected cohort included in the follow-up and its prospective design. This was possible because
Table 3 Uni- and multivariate regression analysis for the presence of urinary incontinence (UI) and pelvic organ prolapse stage II+ (POP II+). Results for variables with $p>0.250$ in univariate analysis are not shown

\begin{tabular}{|c|c|c|c|c|}
\hline \multirow[b]{2}{*}{$n=987$} & \multicolumn{2}{|l|}{ Univariate analysis } & \multicolumn{2}{|l|}{ Multivariate analysis } \\
\hline & OR $(95 \% \mathrm{CI})$ & $p$ & OR $(95 \% \mathrm{CI})$ & $p$ \\
\hline \multicolumn{5}{|l|}{ UI } \\
\hline Age (per additional year of age) & $1.084(1.041-1.129)$ & 0.0001 & $1.088(1.044-1.134)$ & 0.0001 \\
\hline Height (per additional cm) & $0.978(0.957-1.000)$ & 0.051 & $0.976(0.837-0.988)$ & 0.030 \\
\hline BMI before pregnancy & $1.071(1.026-1.119)$ & 0.002 & $1.081(1.035-1.130)$ & 0.001 \\
\hline BMI at delivery & $1.029(0.991-1.068)$ & 0.130 & & Excl. \\
\hline BMI increase & $0.899(0.8285-0.976)$ & 0.010 & $0.902(0.828-0.979)$ & 0.014 \\
\hline \multicolumn{5}{|l|}{ POP II+ } \\
\hline Age & $1.081(1.023-1.143)$ & 0.006 & $1.082(1.024-1.144)$ & 0.005 \\
\hline $\begin{array}{l}\text { Duration of the first stage (per } \\
\text { additional minute) }\end{array}$ & $0.999(0.998-1.000)$ & 0.035 & $0.999(0.098-1.000)$ & 0.032 \\
\hline $\begin{array}{l}\text { Duration of the second stage } \\
\text { (per additional minute) }\end{array}$ & $0.996(0.990-1.002)$ & 0.238 & & Excl. \\
\hline Foetal weight (per additional gram) & $1.000(1.000-1.001)$ & 0.144 & & Excl. \\
\hline Use of analgesics other than epidural & $0.792(0.537-1.168)$ & 0.247 & & Excl. \\
\hline
\end{tabular}


Table 4 Uni- and multivariate regression analysis for presence of any levator ani avulsion (LAM avulsion) and ballooning without LAM avulsion. Results for variables with $p>0.250$ in univariate analysis are not shown

\begin{tabular}{|c|c|c|c|c|}
\hline \multirow[b]{2}{*}{$n=987$} & \multicolumn{2}{|l|}{ Univariate analysis } & \multicolumn{2}{|l|}{ Multivariate analysis } \\
\hline & OR $(95 \% \mathrm{CI})$ & $p$ & OR $(95 \% \mathrm{CI})$ & $p$ \\
\hline \multicolumn{5}{|l|}{ LAM avulsion } \\
\hline Age (per additional year of age) & $1.038(0.995-1.082)$ & 0.081 & & Excl \\
\hline Initial BMI & $0.964(0.917-1.014)$ & 0.152 & & Excl \\
\hline Delivery BMI & $0.964(0.924-1.006)$ & 0.093 & $0.952(0.910-0.996)$ & 0.032 \\
\hline $\begin{array}{l}\text { Duration of the second stage } \\
\text { (per additional minute) }\end{array}$ & $1.006(1.002-1.011)$ & 0.007 & $1.005(1.000-1.009)$ & 0.044 \\
\hline Foetal weight (per additional gram) & $1.001(1.000-1.001)$ & 0.003 & $1.001(1.000-1.001)$ & 0.007 \\
\hline Forceps delivery & $4.841(2.006-11.679)$ & 0.0001 & $3.217(1.538-8.223)$ & 0.015 \\
\hline Epidural analgesia & $0.633(0.410-0.978)$ & 0.042 & $0.576(0.370-0.898)$ & 0.015 \\
\hline Episiotomy & $1.271(0.920-1.755)$ & 0.150 & & Excl \\
\hline Perineal rupture grade I & $0.466(0.272-0.798)$ & 0.004 & $0.495(0.286-0.854)$ & 0.012 \\
\hline \multicolumn{5}{|l|}{ Ballooning without LAM avulsion } \\
\hline Age (per additional year of age) & $1.061(1.010-1.115)$ & 0.019 & $1.075(1.022-1.131)$ & 0.005 \\
\hline Initial BMI & $1.059(1.005-1.116)$ & 0.015 & $1.066(1.010-1.125)$ & 0.019 \\
\hline Delivery BMI & $1.033(0.987-1.082)$ & 0.162 & & Excl \\
\hline $\begin{array}{l}\text { Duration of the second stage } \\
\text { (per additional minute) }\end{array}$ & $0.993(0.987-0.999)$ & 0.017 & $0.992(0.986-0.998)$ & 0.008 \\
\hline Perineal rupture grade III & $0.347(0.082-1.475)$ & 0.208 & & Excl \\
\hline Epidural analgesia & $1.564(1.016-2.409)$ & 0.053 & $1.644(1.059-2.551)$ & 0.027 \\
\hline Episiotomy & $0.671(0.470-0.956)$ & 0.030 & & Excl \\
\hline Perineal rupture grade I & $1.739(1.084-2.790)$ & 0.029 & $1.788(1.103-2.899)$ & 0.018 \\
\hline Use of analgesics other than epidural & $0.711(0.498-1.016)$ & 0.065 & & Excl \\
\hline
\end{tabular}

To a certain extent, we have contributed to the discussion on risk factors related to PFD. Maternal age and weight were again identified as essential factors in the development of UI and POP. It seems that EDA may have a protective effect against LAM avulsion, but at the same time, it may contribute to micro-traumatization and the development of ballooning. To make a stronger conclusion on EDA impact, we would need more research. The effect of perineal rupture grade I may represent a link between the intrinsic properties of the tissues that allow some primiparous women to deliver with only minor injuries but predispose them to overstretched tissue.

Acknowledgements We are grateful for the support of several clinicians and midwives for their help with patient recruitment. Special thanks to research nurses from the urogynecological office of the institute, namely, Lydie Bilova, Katerina Fenclova and Simona Maluskova, who performed all clinical examinations and data collection during the entire study.

Funding Supported from the Institute for the Care of Mother and Child.

\section{Compliance with ethical standards}

\section{Conflict of interest None.}

Open Access This article is distributed under the terms of the Creative Commons Attribution 4.0 International License (http:// creativecommons.org/licenses/by/4.0/), which permits unrestricted use, (PFT, weight reduction, etc.). 
distribution, and reproduction in any medium, provided you give appropriate credit to the original author(s) and the source, provide a link to the Creative Commons license, and indicate if changes were made.

\section{References}

1. Milsom I, Altman D, Lapitan MC, et al. Epidemiology of urinary (UI) and faecal (FI) incontinence and pelvic organ prolapse (POP). Paris: Health Publication Ltd; 2009.

2. Bortolini MAT, Drutz HP, Lovatsis D, Alarab M. Vaginal delivery and pelvic floor dysfunction: current evidence and implications for future research. Int Urogynecol J Pelvic Floor Dysfunct. 2010;21: 1025-30. https://doi.org/10.1007/s00192-010-1146-9.

3. DeLancey JOL, Kane Low L, Miller JM, et al. Graphic integration of causal factors of pelvic floor disorders: an integrated life span model. Am J Obstet Gynecol. 2008;199:610.e1-5. https://doi.org/ 10.1016/j.ajog.2008.04.001.

4. Callewaert G, Albersen M, Janssen K, et al. (2015) The impact of vaginal delivery on pelvic floor function - delivery as a time point for secondary prevention: A commentary. BJOG An Int J Obstet Gynaecol 678-681. https://doi.org/10.1111/1471-0528.13505.

5. Memon HU, Blomquist JL, Dietz HP, et al. Comparison of levator ani muscle avulsion injury after forceps-assisted and vacuumassisted vaginal childbirth. Obstet Gynecol. 2015;125:1080-7. https://doi.org/10.1097/AOG.0000000000000825.

6. Glazener C, Elders A, MacArthur C, et al. Childbirth and prolapse: long-term associations with the symptoms and objective measurement of pelvic organ prolapse. BJOG An Int J Obstet Gynaecol. 2013;120:161-8. https://doi.org/10.1111/1471-0528.12075.

7. Rortveit G, Daltveit AK, Hannestad YS, Hunskaar S. Vaginal delivery parameters and urinary incontinence: the Norwegian EPINCONT study. Am J Obstet Gynecol. 2003;189:1268-74. https://doi.org/10.1067/S0002-9378(03)00588-X.

8. Dietz HP, Simpson JM. Does delayed child-bearing increase the risk of levator injury in labour? Aust N Z J Obstet Gynaecol. 2007;47:491-5. https://doi.org/10.1111/j.1479-828X.2007.00785. $\mathrm{x}$

9. Avery K, Donovan J, Peters JF. ICIQ: a brief and robust measure for evaluating the symptoms and impact of urinary incontinence. Neurourol Urodyn. 2004;23:322-30.

10. Rogers R, Coates K, Kammerer-Doak D, et al. A short form of the pelvic organ prolapse/urinary incontinence sexual questionnaire, (PISQ-12). Int Urogynecol J Pelvic Floor Dysfunct. 2003;14:1648. https://doi.org/10.1007/s00192-003-1063-2.

11. Bump RC, Mattiasson A, Bo K. The standardization of terminology of fiale pelvic organ prolapse and pelvic floor dysfunction. Am J Obs Gynecol. 1996;175:10-7.

12. Bø K, Finckenhagen HB. Vaginal palpation of pelvic floor muscle strength: inter-test reproducibility and comparison between palpation and vaginal squeeze pressure. Acta Obstet Gynecol Scand. 2001;80:883-3. https://doi.org/10.1080/791200641.

13. Wiegersma M, Panman CMCR, Kollen BJ, et al. Is the hymen a suitable cut-off point for clinically relevant pelvic organ prolapse? Maturitas. 2017;99:86-91. https://doi.org/10.1016/j.maturitas. 2017.02.012.

14. Dietz HP. Ultrasound imaging of the pelvic floor. Part II: threedimensional or volume imaging. Ultrasound Obstet Gynecol. 2004;23:615-25. https://doi.org/10.1002/uog.1072.
15. ICS/IUJA Terminology Committees (2010) an International Urogynecological Association ( IUGA ) / International Continence Society ( ICS ) Joint Report on the Terminology.

16. O'Driscoll K, Stronge JM, Minogue M. Active management of labour. Br Med J. 1973;3:135-7. https://doi.org/10.1016/S01406736(87)90401-6.

17. Bl S, Wl L, Zeng Y, et al. Early versus late initiation of epidural analgesia for labour ( review ) early versus late initiation of epidural analgesia for labour. Copyright; 2014. p. 2-4. https://doi.org/10. 1002/14651858.CD007238.pub2.

18. Jansova M, Kalis V, Rusavy Z, et al. Modeling manual perineal protection during vaginal delivery. Int Urogynecol J Pelvic Floor Dysfunct. 2014;25:65-71. https://doi.org/10.1007/s00192-0132164-1.

19. Omih EE, Lindow S. Impact of maternal age on delivery outcomes following spontaneous labour at term. J Perinat Med. 2015;2015: 773-7. https://doi.org/10.1515/jpm-2015-0128.

20. Rogers R, Gilson GJ, Miller AC, et al. Active management of labor: does it make a difference? Am J Obs Gynecol. 1997;177:599-605.

21. Velebil P (2012) Czech Republic and obstetrical interventions. Entre Nuos 26-27.

22. Rortveit G, Daltveit AK, Hannestad YS, Hunskaar S. Urinary incontinence after vaginal delivery or cesarean section. N Engl J Med. 2003;348:900-7. https://doi.org/10.1056/NEJMoa021788.

23. Diez-Itza I, Aizpitarte I, Becerro A (2007) Risk factors for the recurrence of pelvic organ prolapse after vaginal surgery: a review at 5 years after surgery. Int Urogynecol J Pelvic Floor Dysfunct 18: 1317-1324. https://doi.org/10.1007/s00192-007-0321-0.

24. Memon H, Handa VL. Pelvic floor disorders following vaginal or cesarean delivery. Curr Opin Obstet Gynecol. 2012;24:349-54. https://doi.org/10.1097/GCO.0b013e328357628b.

25. CM a G, MacArthur C, Hagen S, et al. Twelve-year follow-up of conservative management of postnatal urinary and faecal incontinence and prolapse outcomes: randomised controlled trial. BJOG An Int J Obstet Gynaecol. 2014;121:112-9. https://doi.org/10.1111/ 1471-0528.12473.

26. Kassis NC, Hamner JJ, Takase-Sanchez MM, et al. If you could see what we see, would it bother you? Int Urogynecol J. 2017;28:59 64. https://doi.org/10.1007/s00192-016-3073-x.

27. Dietz HP, Garnham AP, Rojas RGG (2015) Is the levator???urethra gap helpful for diagnosing avulsion? Int Urogynecol J Pelvic Floor Dysfunct 1-5. https://doi.org/10.1007/s00192-015-2909-0.

28. Krofta L, Otčenášek M, Kašíková E, Feyereisl J. Pubococcygeuspuborectalis trauma after forceps delivery: evaluation of the levator ani muscle with 3D/4D ultrasound. Int Urogynecol J Pelvic Floor Dysfunct. 2009. https://doi.org/10.1007/s00192-009-0837-6.

29. Hauckv YL, Lewis L, Nathan EA, et al. Risk factors for severe perineal trauma during vaginal childbirth: a Western Australian retrospective cohort study. Women and Birth. 2015;28:16-20.

30. Aasheim V, Nilsen ABV, Reinar LM, Lukasse M. Perineal techniques during the second stage of labour for reducing perineal trauma. Cochrane Database Syst Rev. 2017. https://doi.org/10.1002/ 14651858.CD006672.pub3.

31. Swift SE, Tate SB, Nicholas J. Correlation of symptoms with degree of pelvic organ support in a general population of women: what is pelvic organ prolapse? Am J Obstet Gynecol. 2003;189: 372-7; discussion 377-379. https://doi.org/10.1067/S00029378(03)00698-7.

Publisher's note Springer Nature remains neutral with regard to jurisdictional claims in published maps and institutional affiliations. 